\title{
Correction to: Introduction: From the Emergence to the Dynamics of Welfare Markets
}

\author{
Clémence Ledoux, Karen Shire, \\ and Franca van Hooren
}

\section{Correction to:}

Chapter 1 in: C. Ledoux et al. (eds.), The Dynamics of Welfare Markets, Work and Welfare in Europe, https://doi.org/10.1007/978-3-030-56623-4_1

The original version of chapter 1, "Introduction: From the Emergence to the Dynamics of Welfare Markets" was previously published with exclusive rights reserved by the Publisher. It has now been converted to open access retrospectively under a CC BY 4.0 license and the copyright holder updated to 'The Author(s)'. The book has also been updated with this change. The pagination of the subsequent chapters has been changed by +2 pages. 